\title{
LA TRATA DE SERES HUMANOS EN ESPAÑA Análisis crítico de la normativa española y propuestas para una mayor protección de la víctima*
}

\author{
HUMAN TRAFFICKING IN SPAIN \\ Critical analysis of the current legislation and proposals for a better \\ protection of victims
}

\author{
Serena Alonso García**
}

\begin{abstract}
RESUMEN: Este trabajo tiene por objeto exponer la problemática de la trata de seres humanos en España, mostrando cómo algunos de los elementos que están presentes en la normativa y los planes de actuación, no resultan adecuados a la hora de afrontar este fenómeno desde una perspectiva de respeto a los derechos humanos de las víctimas. Para ello, tras la definición del concepto y su diferenciación con figuras afines, se procederá a hacer un repaso por las exigencias que derivan de la legislación internacional, determinando posteriormente el grado de adecuación del ordenamiento español a las mismas, así como las carencias detectadas. A continuación, se analizará el mecanismo de identificación de las víctimas tal y como está estipulado en España, resaltando sus posibles efectos adversos en relación con los procesos de victimización secundaria. Por último, y sobre la base del estudio comparado de los ordenamientos de siete países europeos, se procede a hacer una serie de recomendaciones que podrían suponer una mejora de la situación de las víctimas, al tiempo que acercarían al Estado español a sus compromisos internacionales en esta materia.
\end{abstract}

ABSTRACT: This paper aims to portray the reality of human trafficking in Spain, where both legislation and public policies have proved inadequate for tackling the issue from a human rights perspective. Hence, after defining the concept of human trafficking, the exigences that derive from the international legislation will be explained. Then, the extent to which the Spanish legal order meets each specific international requirement will be examined. The mechanism established in Spain for identifying victims of human trafficking will also be called into question, as its lack of sensitivity may be triggering secondary victimization sentiments among the victims. Lastly, a comparative analysis of another seven European legal orders will be carried out as a means to provide the Spanish State with specific recommendations for ameliorating its overall approach to human trafficking.

PAlabras Clave: Código Penal Español, Convenio de Varsovia, derechos humanos, identificación, Protocolo de Palermo, trata de seres humanos, victimización secundaria.

KEYWORDS: Spanish Penal Code, Warsaw Convention, human rights, human trafficking, identification, Palermo Protocol, secondary victimization.

Fecha de recepción: 09/09/2020

Fecha de aceptación: 04/11/2020

doi: https://doi.org/10.20318/universitas.2020.5869

\footnotetext{
* Este artículo surge de los TFG de la autora en el doble grado en Derecho y Ciencias Políticas de la Universidad Carlos III de Madrid, puntuados con sobresaliente y propuestos para Matrícula de Honor.

** Graduada por el doble grado en Derecho y Ciencias Políticas de la Universidad Carlos III de Madrid. E-mail: serenaalonso@gmail.com
} 


\section{1.- INTRODUCCIÓN}

Cuando hablamos de trata de seres humanos nos referimos a uno de los tres negocios más lucrativos del mundo, el cual supone la captación y el traslado de personas para su posterior explotación en diversos ámbitos, tales como la industria del sexo, la agricultura o el tráfico de órganos.

Pese al carácter cruel e inhumano de este fenómeno, la trata de personas ha tenido lugar en muchos momentos a lo largo de la historia, afectando siempre a los grupos más vulnerables de la sociedad. Así, realidades como la trata de esclavos o la trata de blancas, resultan ser claros antecedentes históricos de lo que actualmente se denomina trata de seres humanos.

Lo que todas estás prácticas tienen en común es que constituyen un gravísimo atentado a los derechos fundamentales y a la dignidad humana, estando ello ampliamente reconocido por la comunidad internacional y la inmensa mayoría de los Estados. Es por esta razón que los instrumentos internacionales que hoy en día se orientan a acabar con este fenómeno, tratan de hacerlo desde una perspectiva respetuosa con los derechos humanos de las víctimas.

No obstante, y pese a los innegables avances teóricos, en la práctica la gran mayoría de las víctimas de trata aun se encuentran en una situación de extrema vulnerabilidad, desprotegidas e indefensas frente a los tratantes. En prácticamente todas las ocasiones, ello se debe al afán de los Estados por controlar la inmigración ilegal, o luchar contra las redes criminales que operan en la sombra; intereses legítimos, pero que terminan por eclipsar el objetivo primordial de proteger a quienes más sufren esta realidad.

El objetivo del presente trabajo es determinar si las leyes y mecanismos implementados por el Estado español, resultan los más adecuados y eficaces a la hora de identificar y asistir a estas personas, demostrándose, de este modo, un verdadero compromiso del país con la mejora de la situación de las víctimas.

A tal fin, en el primer capítulo abordo una contextualización del fenómeno que abarca desde su definición y diferenciación con figuras afines, hasta la obligación positiva que recae sobre los Estados en lo relativo a la lucha contra la trata y la protección de sus víctimas.

Posteriormente, en el capítulo segundo hago un recorrido por las exigencias derivadas de la legislación internacional y regional en la materia; al tiempo que en el tercero examino el cumplimiento de éstas por parte del ordenamiento español, detallando, a su vez, las carencias detectadas en el mismo.

En el cuarto capítulo exploro los mecanismos que utiliza el Estado español para identificar a las víctimas de trata, de nuevo exponiéndose sus carencias y cómo éstas afectan a los procesos de victimización secundaria que sufren quienes han sido, o son, víctimas de este fenómeno. 
En el quinto y último capítulo planteo un análisis comparado a partir del estudio de mecanismos y prácticas que ya han sido implementados por otros países europeos y que podrían resultar adecuados a la realidad española. El trabajo finaliza con cinco recomendaciones para la mejora de la situación de las víctimas de trata en el Estado español.

\section{2.- EL CONCEPTO DE TRATA DE SERES HUMANOS}

Siguiendo las definiciones establecidas por el artículo 3 del Protocolo de Palermo ${ }^{1}$ y artículo 4 del Convenio del Consejo de Europa, ${ }^{2}$ el fenómeno de "trata de seres humanos" consta de tres elementos fundamentales e indispensables: los actos de reclutar, transportar, alojar y/o recibir a la persona; los medios empleados para ello, entre los que se encuentran la amenaza, la fuerza, el secuestro, el engaño o el aprovechamiento de una situación de vulnerabilidad; y la finalidad de explotación, ${ }^{3}$ no siendo necesario que ésta se produzca para poder hablar de trata. ${ }^{4}$

Este negocio, que se encuentra entre los tres más lucrativos del mundo, junto al tráfico ilegal de drogas y armas, y que se caracteriza por los altos niveles de violencia y coacción a los que están sometidas las víctimas, ${ }^{5}$ afecta sobre todo a grupos vulnerables, convirtiéndose así niños, mujeres, y personas con discapacidad en objetivo predilecto de los tratantes. ${ }^{6}$

\footnotetext{
${ }^{1}$ Protocolo para prevenir, reprimir y sancionar la trata de personas, especialmente mujeres y niños, que complementa la Convención de las Naciones Unidas contra la Delincuencia Organizada Transnacional. Disponible en:

https://www.ohchr.org/documents/professionalinterest/protocoltraffickinginpersons sp.pdf

${ }^{2}$ Consejo de Europa: Convenio del Consejo de Europa sobre la lucha contra la trata de seres humanos, Varsovia, 2005. Disponible en:

https://www.idhc.org/img/butlletins/files/ConveniodeConsejoEuropaTrata\%281\%29 .pdf

${ }^{3}$ Instituto de Derechos Humanos Bartolomé de las Casas. (2019). Trata de seres humanos con fines de explotación sexual: un estudio comparado sobre la detección e identificación de las víctimas, p. 9. Disponible en:

https://clinicajuridicaidhbc.files.wordpress.com/2019/09/informe-clinicaidhbc-tratade-seres-humanos.pdf

4 VILLACAMPA ESTIARTE, C.: "El delito de trata de personas: análisis del nuevo artículo 177 Bis del Código Penal desde la óptica del cumplimiento de compromisos internacionales de incriminación", Anuario da Facultade de Dereito da Universidade da Coruña, 2010, p. 828. Disponible en:

https://repositori.udl.cat/bitstream/handle/10459.1/46637/017383.pdf?sequence= 1\&isAllowed $=y$

${ }^{5}$ United Nations Office on Drugs and Crime. (2018). Global Report on Trafficking in

Persons. Disponible en:

https://www.unodc.org/documents/data-and-

analysis/glotip/2018/GLOTiP_2018_BOOK_web_small.pdf

6 Naciones Unidas, Oficina del Alto Comisionado de los Derechos Humanos: "Los Derechos Humanos y la Trata de Personas", 2014, p. 8. Disponible en:

https://www.ohchr.org/documents/publications/fs36_sp.pdf
} 
Al mismo tiempo, no cabe olvidar la perspectiva de género que opera en este fenómeno, ${ }^{7}$ estando la trata de mujeres y niñas hoy en día considerada como una forma más de violencia de género y de discriminación contra la mujer. ${ }^{8}$

\section{1.- Modalidades de trata según su finalidad}

Siguiendo el Protocolo de Palermo, los fines de explotación requeridos para entender una determinada situación como un supuesto de trata de seres humanos han de ser: el aprovechamiento de la prostitución u otras formas de explotación sexual, los trabajos o servicios forzados, la esclavitud o las prácticas análogas a la esclavitud, la servidumbre o la extracción de órganos. ${ }^{9}$ Adicionalmente, en España, el artículo 177 Bis del Código Penal recoge la trata con fines de mendicidad y matrimonio forzoso. ${ }^{10}$

De acuerdo con la memoria presentada por la Fiscalía General del Estado en 2019, en nuestro país la trata con fines de explotación sexual se mantiene como la modalidad más común, habiendo no obstante casos extremadamente graves del resto de formas, a excepción de aquélla que promueve la extracción de órganos, por completo residual. ${ }^{11}$

Siguiendo a Santos Martín y Martín Ríos, sumado a la facilidad de movimiento internacional de personas y mercancías, los factores que actualmente facilitan la trata de personas a nivel global son los desequilibrios económicos entre países, los conflictos políticos o armados, y también los mercados laborales, cada vez más precarizados. ${ }^{12}$ No obstante, la falta de datos continúa siendo uno de los grandes obstáculos a la hora de medir y determinar la magnitud de este fenómeno en sus distintas versiones, viéndose por ello muy dificultada la lucha contra el mismo. ${ }^{13}$

\footnotetext{
7 AGUILA LARA, M.: "La Trata de Seres Humanos con Fines de Explotación Sexual", Revista Internacional de Pensamiento Político, 2014, p. 402.

8 Fiscalía General del Estado. Memoria elevada al Gobierno de S.M., 2019, p. 18. Disponible en:

https://www.fiscal.es/memorias/memoria2019/FISCALIA_SITE/index.html

9 Protocolo para prevenir, reprimir y sancionar la trata de personas, especialmente mujeres y niños, que complementa la Convención de las Naciones Unidas contra la Delincuencia Organizada Transnacional. Disponible en:

https://www.ohchr.org/documents/professionalinterest/protocoltraffickinginpersons sp.pdf

10 Ley Orgánica 10/1995, de 23 de noviembre, del Código Penal. Disponible en:

https://www.boe.es/buscar/act.php?id=BOE-A-1995-25444

11 Fiscalía General del Estado. Memoria elevada al Gobierno de S.M., 2019, p. 18.

Disponible en:

https://www.fiscal.es/memorias/memoria2019/FISCALIA_SITE/index.html

12 SANTOS MARTÍN, J. y MARTÍN RÍOS, P.: La tutela de la víctima de trata: una perspectiva penal, procesal e internacional, Bosch Editor, Barcelona, 2019, p. 38.

13 United Nations Office on Drugs and Crime. (2018). Global Report on Trafficking in Persons. p, 30. Disponible en:
} 


\section{2.- Diferenciación entre la trata y el tráfico ilícito de personas}

Dado que ambos fenómenos se caracterizan por el traslado territorial de personas, muchos gobiernos tratan de abordarlos de la misma forma, motivo por el que imperan las medidas policiales y de control de fronteras, respecto de aquellas que aspiran a proteger los derechos humanos de las víctimas. ${ }^{14}$

No obstante, tal como expone Díaz Barrado, la trata de seres humanos ha ser objeto de una normativa específica, dado que la prevención y la lucha contra este fenómeno de ir mucho más lejos que cualquier política migratoria. ${ }^{15}$

A su vez, tal como recalca la STS 188/2016, 4 de marzo, entre ambos fenómenos existen profundas diferencias; entre ellas la exigencia de tres elementos adicionales para calificar un supuesto de trata de personas: la captación indebida del individuo, con violencia, intimidación, engaño, coacción o abuso de poder; y la finalidad de explotación, aun si esta no se diere finalmente.

Otra diferencia sustancial entre estas realidades tiene que ver con las ganancias obtenidas a través del delito, dado que, mientras en los casos de trata son el producto de la explotación de la víctima, en el tráfico ilícito de personas provienen del precio pagado por el migrante que desea cruzar la frontera, no teniendo por qué existir relación alguna entre éste y el traficante tras la llegada a destino. ${ }^{16}$

A su vez, el tráfico ilícito de personas cuenta siempre con carácter transnacional, dado que el sujeto pasivo de la acción tiene que ser un ciudadano extranjero extracomunitario, ${ }^{17}$ de manera que el bien jurídico protegido por el artículo 318 bis es el interés del Estado español en controlar los flujos migratorios. Por el contrario, en supuestos de trata de seres humanos la víctima puede provenir de cualquier país y el bien jurídico protegido es la dignidad humana.

No obstante, ambos fenómenos pueden superponerse, ya que, en multitud de casos, el traslado de la víctima comienza de forma voluntaria, equiparándose al supuesto de tráfico ilícito, y es posteriormente, durante el viaje o en el país de destino, cuando los mecanismos coercitivos comienzan a emplearse y ambas realidades se

https://www.unodc.org/documents/data-and-

analysis/glotip/2018/GLOTiP_2018_BOOK_web_small.pdf

14 Red Española Contra la Trata de Personas. (2008). Guía Básica para la identificación, derivación y protección de las personas víctimas de trata con fines de explotación sexual, pp. 7 - 11. Disponible en:

file:///C:/Users/itzin/Downloads/Guia_Basica_Identificacion.pdf

15 DÍAZ BARRADO, C.: "La lucha contra la trata de seres humanos en la Unión Europea: Ios componentes para una política propia", Revista de Derecho Comunitario Europeo, 2017, pp. 495-496.

${ }^{16}$ STS $188 / 2016$

17 Gracias a la Directiva 2004/38/CE, cualquier ciudadano europeo puede vivir en otro país de la UE durante un período máximo de 3 meses sin estar sometidos a condiciones ni formalidades. 
disocian. ${ }^{18}$ Esta voluntariedad parece lógica cuando se entiende que, aunque la captación de las personas en el país de origen suelen llevarla a cabo redes criminales organizadas, el primer contacto con las víctimas normalmente lo desarrolla un captador individual, en muchos casos conocido o familiar, quien le promete acceso a trabajo legítimo y a mejores expectativas de vida en el país de destino. ${ }^{19}$

A ello se suma que, en la práctica, resulta altamente factible el asimilar una víctima de trata con un migrante que pretende acceder irregularmente al territorio. ${ }^{20}$ Ello plantea graves problemas puesto que, desde el momento en que una persona se convierte en víctima de trata, al ser su necesidad de protección frente a nuevos procesos de victimización ciertamente superior, debe recibir de forma inmediata servicios específicos de asistencia y protección, los cuales no se encuentran al alcance del migrante introducido de forma ilícita en el territorio español. ${ }^{21}$ Tales exigencias se encuentran claramente recogidas en la legislación internacional y en el Manual de Naciones Unidas Para la Lucha Contra la Trata de Personas.

La identificación de la víctima de trata se convierte así en la piedra angular de todo el proceso de recuperación y asistencia, al ser este reconocimiento del que parten el resto de los mecanismos de protección que Estados como el español, están obligados a proporcionar.

\section{3.- Diligencia debida y obligación positiva de los Estados}

Tal como explican Santos Martín y Martín Ríos, en la actualidad las instancias internacionales intentan abordar la trata de personas desde un enfoque holístico y de derechos humanos, al entender que este fenómeno supone la vulneración de bienes jurídicos personalísimos, tales como el derecho a la vida, a la salud y a la libertad. 22

Es por ello por lo que, tanto la Asamblea General de las Naciones Unidas, como el Consejo de Derechos Humanos han reconocido la

18 Defensor del Pueblo. (2012). La trata de seres humanos en España: víctimas invisibles, p. 34. Disponible en:

https://www.defensordelpueblo.es/wp-content/uploads/2015/05/2012-09-Tratade-seres-humanos-en-Espa\%C3\%B1a-v\%C3\%ADctimas-invisibles-ESP.PDF

19 Red Española Contra la Trata de Personas. (2008). Guía Básica para la identificación, derivación y protección de las personas víctimas de trata con fines de explotación sexual, pp. 7 - 11. Disponible en:

file:///C:/Users/itzin/Downloads/Guia_Basica_Identificacion.pdf

20 Defensor del Pueblo. (2012). La trata de seres humanos en España: víctimas invisibles, p. 34. Disponible en:

https://www.defensordelpueblo.es/wp-content/uploads/2015/05/2012-09-Tratade-seres-humanos-en-Espa\%C3\%B1a-v\%C3\%ADctimas-invisibles-ESP.PDF

21 Naciones Unidas. (2007). Manual para la lucha contra la trata de personas. Disponible en: https://www.unodc.org/pdf/Trafficking_toolkit_Spanish.pdf

22 SANTOS MARTIN, J. y MARTÍN RÍOS, P.: La tutela de la víctima de trata: una perspectiva penal, procesal e internacional, Bosch Editor, Barcelona, 2019, p. 158. 
aplicabilidad del principio de diligencia debida en materia de trata de seres humanos. ${ }^{23}$ En virtud de este, desde el momento en que un Estado no proteja, respete, promueva o cumpla sus obligaciones en la materia respecto de cualquier persona que se encuentre dentro de su jurisdicción, adquirirá una responsabilidad jurídica en el plano internacional. ${ }^{24}$

A su vez, en 2005, a raíz del caso Siliadin contra Francia, el Tribunal Europeo de Derechos Humanos (TEDH) determinó que sobre los Estados recae la obligación positiva de penalizar y enjuiciar todo acto que se dirija a mantener a un individuo sometido a cualquiera de las situaciones que recoge el Artículo 4 del Convenio Europeo de Derechos Humanos (CEDH), a partir del que se prohíbe la esclavitud y el trabajo forzado, al consagrar este uno de los valores fundamentales de cualquier sociedad democrática. ${ }^{25}$

Cinco años después, con la sentencia Rantsev contra Rusia y Chipre, el mismo Tribunal recordó de nuevo las obligaciones positivas de los Estados, esta vez en relación con la efectiva investigación de aquellos casos en los que existe sospecha de trata de personas. Así, el TEDH vuelve a identificar el fenómeno como una vulneración del artículo 4 del CEDH, al tiempo que lo define como una amenaza a la dignidad y a los derechos humanos de las víctimas. ${ }^{26}$

\section{3.- EXIGENCIAS DERIVADAS DE LA LEGISLACIÓN INTERNACIONAL}

\section{1.- Protocolo para prevenir, reprimir y sancionar la trata de personas, especialmente mujeres y niños}

También denominado "Protocolo de Palermo", establece la primera definición consensuada de la trata de seres humanos, ${ }^{27}$ al tiempo que estipula la obligación de cada Estado Parte de adoptar las medidas que resulten necesarias para tipificar como delito la conducta anteriormente definida.

\footnotetext{
23 Defensor del Pueblo. (2012). La trata de seres humanos en España: víctimas invisibles, p. 41. Disponible en: https://www.defensordelpueblo.es/wpcontent/uploads/2015/05/2012-09-Trata-de-seres-humanos-en-Espa\%C3\%B1aV\%C3\%ADctimas-invisibles-ESP.PDF

24 Defensor del Pueblo. (2012). La trata de seres humanos en España: víctimas invisibles, p. 40. Disponible en: https://www.defensordelpueblo.es/wpcontent/uploads/2015/05/2012-09-Trata-de-seres-humanos-en-Espa\%C3\%B1aV\%C3\%ADctimas-invisibles-ESP.PDF

${ }^{25}$ STEDH (Sección 2a). Siliadin contra Francia, 26 octubre de 2005, pár. 89 y 112.

${ }^{26}$ STEDH (Sección $1^{a}$ ). Ranstsev contra Chipre y Rusia, 7 enero de 2010, pár. 298 y 300.

27 Instituto de Derechos Humanos Bartolomé de las Casas. (2019). Trata de seres humanos con fines de explotación sexual: un estudio comparado sobre la detección e identificación de las víctimas, p. 8. Disponible en:

https://clinicajuridicaidhbc.files.wordpress.com/2019/09/informe-clinicaidhbc-tratade-seres-humanos.pdf
} 
Posteriormente, en su artículo 6, dedicado a la asistencia y protección de las víctimas de trata de personas, este Protocolo anima a los Estados a considerar la aplicación de medidas que permitan la recuperación física, psicológica y social de estas víctimas, así como mecanismos que les brinden la posibilidad de obtener indemnizaciones por los daños sufridos. ${ }^{28}$

En España, esta norma entró en vigor el 25 de diciembre de 2003, siendo desde entonces todo su contenido vinculante para nuestro país. ${ }^{29}$

\section{2.- Convenio del Consejo de Europa sobre la lucha contra la trata de seres humanos}

Comúnmente denominado "Convenio de Varsovia", este instrumento tiene por objetivo facilitar la prevención, la investigación y la sanción del delito de trata de personas, así como la protección y promoción de los derechos de las víctimas, instando a la cooperación internacional y la asunción de las responsabilidades de los Estados en esta materia. 30

Entre los derechos que reconoce a las víctimas se encuentran: el derecho a ser identificadas como víctimas de trata de personas; el derecho a recuperarse y a gozar de un periodo de reflexión de al menos 30 días de duración; y el derecho a asistencia jurídica gratuita y a asistencia social. A su vez, el texto establece que, en función de su situación personal, las víctimas deben poder acceder a permisos de residencia en el Estado receptor, así como a un retorno seguro y asistido a sus países de origen. ${ }^{31}$

Con el fin de dar seguimiento al cumplimiento de las disposiciones del texto, el Capítulo VII del Convenio constituye el Grupo de expertos sobre la lucha contra la trata de seres humanos, también

28 Oficina de las Naciones Unidas contra la Droga y el Delito: "Convención de las Naciones Unidas contra la delincuencia organizada transnacional y sus protocolos", Nueva York, 2014. Disponible en:

https://www.unodc.org/documents/treaties/UNTOC/Publications/TOC\%20Conventio n/TOCebook-s.pdf

29 Instrumento de Ratificación del Protocolo para prevenir, reprimir y sancionar la trata de personas, especialmente mujeres y niños, que complementa la Convención de las Naciones Unidas contra la delincuencia organizada transnacional, hecho en Nueva York el 15 de noviembre de 2000. Disponible en: https://www.boe.es/diario_boe/txt.php?id=BOE-A-2003-22719

30 Instituto de Derechos Humanos Bartolomé de las Casas: "Trata de seres humanos con fines de explotación sexual: un estudio comparado sobre la detección e identificación de las víctimas", 2019, p. 8. Disponible en:

https://clinicajuridicaidhbc.files.wordpress.com/2019/09/informe-clinicaidhbc-tratade-seres-humanos.pdf

${ }^{31}$ Convenio del Consejo de Europa sobre la lucha contra la trata de seres humanos, Varsovia, 16 de mayo de 2005. Disponible en:

https://www.idhc.org/img/butlletins/files/ConveniodeConsejoEuropaTrata\%281\%29 .pdf 
conocido como GRETA, 32 comprometiéndose todos los países signatarios a ser periódicamente evaluados a través de un informe en el que se identifiquen tanto las buenas prácticas como las carencias, llevándose a cabo recomendaciones. ${ }^{33}$

Este Convenio entró en vigor en España el 2 de septiembre de 2009, pasando nuestro país a estar vinculado por todo su contenido. ${ }^{34}$

\section{3.- Directiva $2004 / 81 / C^{35}$}

Este instrumento atañe a la expedición de permisos de residencia a aquellos nacionales de terceros países que sean víctimas de la trata de seres humanos y que hayan decidido cooperar con las autoridades competentes en la lucha contra esta lacra.

En su artículo 6 estipula la obligación de los Estados Miembros de establecer un periodo de reflexión que permita a las víctimas recuperarse y sopesar la decisión de cooperar con la investigación del delito. Posteriormente, el artículo 7 establece la obligación de dar a las víctimas acceso a medios que permitan su subsistencia a lo largo de este periodo, así como a tratamiento médico de urgencia, al tiempo que alientan a los Estados a asegurar la asistencia jurídica gratuita.

Una vez transcurrido el periodo de reflexión, siguiendo el artículo 8 , de mostrarse la víctima dispuesta a colaborar y haber cortado toda relación con los presuntos autores del delito, deberá otorgársele un permiso de residencia de mínimo 6 meses de duración.

A ojos de Villacampa Estiarte, la estrecha conexión trazada entre la concesión este permiso y la predisposición de la víctima a cooperar muestra claramente que el documento estudiado enfoca la problemática desde una perspectiva criminocéntrica. ${ }^{36}$

Por último, el artículo 12 establece la obligación de que las víctimas puedan acceder a planes y programas formativos, capaces de ayudarles a recuperar cierta normalidad en su vida social.

32 Convenio del Consejo de Europa sobre la lucha contra la trata de seres humanos, Varsovia, 16 de mayo de 2005. Disponible en:

https://www.idhc.org/img/butlletins/files/ConveniodeConsejoEuropaTrata\%281\%29 .pdf

33 Consejo de Europa: Derechos de las Víctimas, España, 2013. Disponible en: https://rm.coe.int/16805d41b7

${ }^{34}$ Instrumento de Ratificación del Convenio del Consejo de Europa sobre la lucha contra la trata de seres humanos (Convenio no 197 del Consejo de Europa), hecho en Varsovia el 16 de mayo de 2005. Disponible en:

https://www.boe.es/diario_boe/txt.php?id=BOE-A-2009-14405

35 Directiva 2004/81/CE del Consejo, de 29 de abril de 2004, relativa a la expedición de un permiso de residencia a nacionales de terceros países que sean víctimas de la trata de seres humanos o hayan sido objeto de una acción de ayuda a la inmigración ilegal, que cooperen con las autoridades competentes. Disponible en: https://www.boe.es/doue/2004/261/L00019-00023.pdf

36 VILLACAMPA ESTIARTE, C.: "La nueva Directiva europea relativa a la prevención y la lucha contra la trata de seres humanos y a la protección de las víctimas", Revista Electrónica de Ciencia Penal y Criminología, 2011, p. 22. 


\section{4.- Directiva $2011 / 36 /$ UE $^{37}$}

Esta Directiva establece los elementos básicos que debe tener la legislación penal de todo Estado Miembro en materia de trata de personas, entre los que se encuentran: el establecimiento a los autores del delito de una pena privativa de libertad de al menos 5 años; la responsabilidad penal de las personas jurídicas; el embargo y decomiso de los instrumentos y productos del delito. Al mismo tiempo, se determina que los Estados no enjuiciarán o impondrán penas a las víctimas por aquellos hechos delictivos que se hubieran visto obligadas a cometer como consecuencia directa de la situación de trata.

Posteriormente, el documento exige que se establezcan mecanismos dirigidos a la identificación temprana de las víctimas, siempre en cooperación con las organizaciones de apoyo pertinentes. A su vez, obliga a los Estados a adoptar medidas de asistencia y apoyo también para las víctimas potenciales, e impide que aquellas destinadas a víctimas ya identificadas formalmente se supediten a la disposición de éstas de colaborar con la investigación del delito.

Por último, establece como necesario que las víctimas reciban un trato especial, orientado a prevenir y evitar los procesos de victimización secundaria. Para ello entiende pertinente que los funcionarios que estén, o puedan estar, en contacto con cualquier potencial víctima, reciban formación periódica sobre cómo identificarlas y tratarlas.

Siguiendo a Villacampa Estiarte, puede decirse que esta Directiva resulta muy novedosa por su visión victimocéntrica, al no estar ya exclusivamente centrada en perseguir a los delincuentes, sino también en proteger a las víctimas, lo que representa un gran avance en lo relativo al reconocimiento de la trata como una grave violación de los derechos humanos. ${ }^{38}$

Al mismo tiempo, tal como expone Escribano Úbeda-Portugués, con esta nueva Directiva la Unión Europea deja claro que ningún Estado miembro puede continuar identificando la lucha contra la trata de seres humanos con una mera dimensión de su política migratoria o de la lucha contra la delincuencia organizada. ${ }^{39}$

\footnotetext{
37 Directiva 2011/36/UE del Parlamento Europeo y del Consejo, de 5 abril de 2011, relativa a la prevención y lucha contra la trata de seres humanos y a la protección de las víctimas y por la que se sustituye la Decisión marco 2002/629/JAI del Consejo. Disponible en:

https://eur-lex.europa.eu/legal-

content/ES/TXT/PDF/?uri=CELEX:32011L0036\&from =en

38 VILLACAMPA ESTIARTE, C.: "La nueva Directiva europea relativa a la prevención y la lucha contra la trata de seres humanos y a la protección de las víctimas", Revista Electrónica de Ciencia Penal y Criminología, 2011, p. 2.

39 ESCRIBANO ÚBEDA-PORTUGUÉS, J.: "Evolución y desarrollos normativos en el derecho internacional y europeo en la lucha contra la trata de personas y el tráfico ilícito de migrantes", Nova et Vetera, 2011, p. 147.
} 


\section{4.- TRANSPOSICIÓN NACIONAL DE LAS EXIGENCIAS INTERNACIONALES}

Ha de partirse del hecho de que España carece de una ley integral que afronte esta problemática desde una perspectiva holística; en su lugar, la actuación de nuestro país está determinada por una pluralidad de normas y políticas públicas, cuya dispersión no ayuda a la lucha efectiva contra esta lacra.

\section{1.- Ley Orgánica 10/1995, de 23 de noviembre, del Código Penal}

Siguiendo a Martos Nuñez, la trata de seres humanos constituye un crimen de lesa humanidad, debiendo estar contenido en el artículo 607 del Código Penal, al suponer un ataque sistemático a los derechos fundamentales de la población civil. ${ }^{40}$ Pese a la coherencia de este argumento, su debate abarcaría un espacio del que no disponemos, y la realidad actual es que, en nuestro país, la tutela penal contra la trata de seres humanos se lleva a cabo a través del artículo 177 Bis. No obstante, ha de reconocerse el camino avanzado, dado que, no fue hasta la reforma operada por la Ley 5/2010 de 22 de junio, que se tipificó en España la trata de seres humanos, ${ }^{41}$ habiendo la posterior LO $1 / 2015$ de 30 de marzo, adaptado el tipo a las exigencias de la Directiva 2011/36/UE. ${ }^{42}$

El bien jurídico protegido por el artículo 177 Bis es, siguiendo a Santos Martín y Martín Ríos ${ }^{43}$ y de acuerdo con la STS 378/2011 de 17 de mayo, ${ }^{44}$ la dignidad de la persona. No obstante, no debemos olvidar que la trata de personas también pone en peligro otros bienes jurídicos de las víctimas, como son los derechos laborales, la libertad sexual, y la integridad física o moral, cuya afectación tendrá lugar si los fines de explotación llegasen efectivamente a materializarse.

A su vez, en todas las modalidades de trata la víctima equivale a una simple mercancía, siendo su único fin proporcionar beneficios a terceros. Es este alto grado de inhumanidad en el iter criminis lo que

40 MARTOS NUÑEZ, J.: "El delito de trata de seres humanos: análisis del artículo 177 Bis del Código Penal", Estudios Penales y Criminológicos, 2012, p. 121.

${ }^{41}$ Ilustre Colegio de Abogados de Madrid. (2016). Trata de Seres Humanos: Artículo 177 Bis del Código Penal. p. 12. Disponible en:

http://web.icam.es/bucket/INFORME\%20TRATA\%20DE\%20SERES\%20HUMANOS.p df

42 Ilustre Colegio de Abogados de Madrid. (2016). Trata de Seres Humanos: Artículo 177 Bis del Código Penal. p. 15. Disponible en:

http://web.icam.es/bucket/INFORME\%20TRATA\%20DE\%20SERES\%20HUMANOS.p df

43 SANTOS MARTÍN, J. y MARTÍN RÍOS, P.: La tutela de la víctima de trata: una perspectiva penal, procesal e internacional, Bosch Editor, Barcelona, 2019, p. 136. 
ha llevado a amplios sectores de la doctrina a referirse a este fenómeno como el "comercio de la miseria humana". 45

Respecto a la condición de sujeto pasivo del delito, siguiendo la STS 910/2013, de 3 de diciembre, ${ }^{46}$ éste será aquel sobre el que recaiga la conducta típica. De esta forma se evita cualquier limitación por razón de nacionalidad, situación administrativa irregular o vulneración de las normas migratorias, lo que resulta de lo más lógico al ser la trata de seres humanos una realidad que en España afecta principalmente a personas no nacionales.

En cualquier caso, del análisis de la redacción del tipo básico, realizado por el Consejo General del Poder Judicial en 2018,47 se extrae que el delito de trata de personas cumple todas las exigencias planteadas por las normas de carácter internacional y regional.

\section{2.- Ley 4/2015, de 27 de abril, del Estatuto de la víctima del delito}

Ya en su preámbulo, esta Ley parte de un concepto amplio de víctima, reconociéndole protección y apoyo extraprocesal. Para ello, la norma determina como fundamental el ofrecimiento a la víctima de facilidades para el ejercicio y la tutela de sus derechos, evitando en la medida de lo posible la victimización secundaria.

El texto reconoce el trato especializado que precisan las víctimas de trata, recalcando que el apoyo a éstas no se limita a la dimensión material, sino que se extiende también a la moral.

Posteriormente, en su artículo 16, prevé la posibilidad de que las víctimas que carezcan de recursos económicos soliciten asistencia jurídica gratuita. Al abarcar este derecho a las víctimas de trata, sin distinción alguna por razón de nacionalidad, se cumplen las exigencias del Convenio de Varsovia y la Directiva 2004/81/CE.

\section{3.- Ley Orgánica $4 / 2000$, de 11 de enero, sobre derechos y libertades de los extranjeros en España y su integración social $(\text { LOEX) })^{48}$}

El artículo 59 Bis de esta norma excluye las medidas de expulsión, devolución o rechazo en frontera en aquellos supuestos en

\footnotetext{
${ }^{45}$ Fiscalía General del Estado. (2019). Memoria elevada al Gobierno de S.M., pp. 69 - 106. Disponible en:

https://www.fiscal.es/memorias/memoria2019/FISCALIA_SITE/index.html

${ }^{46}$ STS $910 / 2013$

47 Consejo General del Poder Judicial. (2018). Guía de Criterios de Actuación Judicial Frente a la Trata de Seres Humanos, pp. 69-113. Disponible en: http://www.poderjudicial.es/cgpj/es/Poder-Judicial/En-Portada/El-CGPJ-presentauna-Guia-de-criterios-de-actuacion-judicial-para-detectar-e-investigar-la-trata-deseres-humanos-con-fines-de-explotacion

48 Ley Orgánica 4/2000, de 11 de enero, sobre derechos y libertades de los extranjeros en España y su integración social. Disponible en: https://www.boe.es/buscar/act.php?id=BOE-A-2000-544
} 
los que el órgano competente considere que existen motivos razonables para creer que la persona extranjera en situación administrativa irregular es, o ha sido, víctima de trata de seres humanos. 49

A su vez, en concordancia con las exigencias de la Directiva 2004/81/CE, esta ley establece un periodo de restablecimiento y reflexión de mínimo 90 días, cuyo fin es otorgar a la víctima la posibilidad de recuperarse y reflexionar sobre lo sucedido, pudiendo así decidir si desea o no, colaborar con las autoridades competentes en la investigación del delito de trata o de otros relacionados.

También se establece que la víctima podrá obtener un permiso de residencia y trabajo, en conjunto con facilidades para su integración social cuando, en circunstancias excepcionales, la autoridad administrativa lo considere necesario en atención a su voluntad de cooperar con la investigación penal o a su situación personal.

\section{4.- Carencias detectadas}

En lo que respecta a la tipificación penal, a pesar de que la redacción del tipo básico se ajusta por completo a las exigencias internacionales, al ser la trata un delito antecedente a la conducta de explotación, la eficacia en su lucha queda siempre condicionada por la manera en que los Estados estipulan el tratamiento del delito final.

Y es que, tal como afirma la Fiscalía General del Estado, todas las modalidades de explotación reconocidas por el artículo 177 Bis constituyen subcategorías de la esclavitud, la servidumbre o el trabajo forzoso. Dentro del Código Penal español, sin embargo, no está tipificada ninguna de estás realidades, por lo que, cuando la finalidad de la trata efectivamente se lleva a cabo y la explotación de la víctima tiene lugar, la única solución que ofrece nuestro ordenamiento penal es el concurso con los delitos contra los derechos de los trabajadores, tipificados en los artículos 311,311 bis y 312.2 .

Ello colisiona con la obligación de perseguir y sancionar a quienes impongan trabajos forzosos u obligatorios, impuesta al Estado Español por el artículo 1 del Protocolo de 2014 relativo al Convenio de 1930 sobre el trabajo forzoso, en vigor desde el 20 septiembre 2017.50 Además, tal como POMARES CINTAS recalca, esta solución resulta ilógica dado que ninguno de los tipos de explotación laboral conlleva la imposición de la prestación misma del trabajo, ${ }^{51}$ al tiempo que, cómo

\footnotetext{
49 Fiscalía General del Estado. (2019). Memoria elevada al Gobierno de S.M, p. 1236. Disponible en:

https://www.fiscal.es/memorias/memoria2019/FISCALIA_SITE/index.html

50 Protocolo de 2014 relativo al Convenio sobre el trabajo forzoso, Ginebra, 28 de mayo de 2014. Disponible en:

https://www.ilo.org/dyn/normlex/es/f?p=NORMLEXPUB:12100:0::NO::P12100_ILO CODE:P029

51 POMARES CINTAS, E.: El Derecho Penal ante la explotación laboral y otras formas de violencia en el trabajo, Tirant lo Blanch, Valencia, 2013, p. 139.
} 
bien explican López Rodriguez y Arrieta Idikez, mientras el artículo 177 Bis tutela la dignidad humana, los delitos contra los derechos de los trabajadores protegen un bien jurídico distinto, los derechos laborales y sociales del individuo. 52

Siguiendo el análisis de la Fiscalía General del Estado, la atipicidad de la esclavitud, la servidumbre y el trabajo forzoso es una de las mayores carencias del ordenamiento jurídico penal español, ya que imposibilita la prevención o persecución eficaz de la trata de personas con fines de explotación laboral. 53

En lo que se refiere al artículo 59 Bis de la LOEX, de nuevo siguiendo el análisis de la Memoria anteriormente citada, éste resulta una transposición meramente parcial de las exigencias internacionales, dado que no ofrece una verdadera protección a las víctimas de trata de seres humanos, quedando su ineficacia reflejada en el escaso número de víctimas que se acogen al mecanismo. ${ }^{54} \mathrm{~A}$ ello se suma que, al estar las previsiones de este artículo dirigidas a nacionales extracomunitarios en situación irregular, no abarcan a todas aquellas víctimas que, aunque no siendo nacionales españolas, provienen de otros Estados Miembros, tales como Rumanía o Bulgaria.

\section{5.- PROBlemas Relativos a los PROCESOS DE IDENTIFICACIÓN DE LAS VÍCTIMAS}

\section{1.- Protocolo Marco de Protección a las Víctimas de Trata de Seres Humanos}

En nuestro país, el proceso de identificación de las víctimas de trata se lleva a cabo a través de los mandatos contenidos en el Protocolo Marco de Protección a las Víctimas de Trata de Seres Humanos. ${ }^{55}$ Este instrumento pretende centrarse en la promoción y protección de los derechos humanos de las víctimas, evitando el fenómeno de la victimización secundaria, y aportando una perspectiva de género a la lucha contra la trata de personas.

\footnotetext{
52 LÓPEZ RODRIGUEZ, J. y ARRIETA IDIKEZ, F.: "La trata de seres humanos con fines de explotación laboral en la legislación española", Revista cuatrimestral de las Facultades de Derecho y Ciencias Económicas y Empresariales, 2019, p. 20.

53 Fiscalía General del Estado. (2019). Memoria elevada al Gobierno de S.M, p. 1265. Disponible en:

https://www.fiscal.es/memorias/memoria2019/FISCALIA_SITE/index.html

${ }^{54}$ Fiscalía General del Estado. (2019). Memoria elevada al Gobierno de S.M, p. 1236.

Disponible en:

https://www.fiscal.es/memorias/memoria2019/FISCALIA_SITE/index.html

55 Ministerios de Justicia, del Interior, de Empleo y Seguridad Social y de Sanidad, Servicios Sociales e Igualdad, Fiscalía General del Estado y el Consejo del Poder Judicial. (2011). Protocolo Marco de Protección a las Víctimas de trata de seres humanos. Disponible en:

https://www.policia.es/trata/pdf/protocolo_marco_trata.pdf
} 


\subsection{1.- Fase de detección}

El documento abre las puertas a detecciones llevadas a cabo, no solo por las Fuerzas y Cuerpos de Seguridad, sino también por la inspección de trabajo, el personal sanitario, la propia víctima, o cualquier persona que tenga conocimiento de la comisión del delito.

A su vez, si durante la instrucción de un expediente de solicitud de protección internacional se aprecian indicios de que el solicitante puede ser víctima de trata, la Oficina de Asilo y Refugio pondrá el supuesto en conocimiento de la Sección de Asilo de la Comisaría General de Extranjería y Fronteras.

Lo mismo ocurre si la aparente víctima es detectada en frontera o en un Centro de Internamiento de Extranjeros (CIE o CITE), con el fin de que la ejecución de la expulsión no tenga lugar hasta la procedente determinación de su estatus. En este último supuesto el Ministerio Fiscal y la Dirección del Centro también habrán de ser informados.

\subsection{2.- Fase de identificación}

El documento estipula que la identificación de las víctimas la llevarán a cabo unidades policiales con formación específica, tratando en todo momento de proteger sus derechos y, en la medida de lo posible, otorgándoles el apoyo jurídico necesario.

La identificación se basa principalmente en una entrevista personal con la víctima potencial, la cual ha de ser llevada a cabo por personal de las Fuerzas y Cuerpos de Seguridad con formación específica. A su vez, y de nuevo, en la medida de lo posible, el ambiente de estas entrevistas habrá de ser el adecuado a las circunstancias personales de la víctima. En este punto, el documento plantea la posibilidad de que otros niveles administrativos, así como las organizaciones especializadas con experiencia en la materia, colaboren en la identificación.

Al finalizar la entrevista se informará a la presunta víctima de las posibilidades de acceso a la asistencia jurídica gratuita, así como de la existencia de organizaciones especializadas.

Más allá de la entrevista personal, para la identificación ha de recabarse información acerca de la situación personal de la presunta víctima, estando en este punto previsto que las organizaciones especializadas del territorio aporten cuanta información entiendan relevante.

Estos dos elementos, en conjunto con una serie de criterios no accesibles al público (Anexo I del Protocolo), serán en los que se apoye la unidad policial competente para determinar si la persona es o no víctima del delito de trata, así como para valorar los riesgos a los que se enfrenta $y$, en su caso, estipular las medidas de protección necesarias. 
Identificada, la víctima será informada acerca de los recursos de protección y asistencia existentes en nuestro país.

\subsubsection{1-Actuaciones específicas con víctimas extranjeras en situación irregular}

Las víctimas identificadas que se encuentren en situación irregular serán informadas sobre la posibilidad de acogerse al periodo de restablecimiento y reflexión de mínimo 90 días, teniendo en tal caso acceso a medios para recuperarse física y psicológicamente, y pudiendo así sopesar si colaboran con las autoridades en la investigación del delito.

Si deciden acogerse a este régimen, la autoridad competente habrá de elevar una propuesta de concesión a la Delegación o Subdelegación del Gobierno de la provincia donde se llevó a cabo la identificación. La resolución deberá estar motivada y ser notificada al interesado o interesada.

De haberse concedido, una vez transcurrido el periodo de reflexión, si la víctima decidiese no colaborar con la investigación, será informada de la posibilidad de solicitar, ante la Delegación o Subdelegación del gobierno, la exención de responsabilidad administrativa por motivo de su situación personal.

\section{2.- Instrucción 6/2016, de la Secretaría de Estado de Seguridad sobre actuaciones de las Fuerzas y Cuerpos de Seguridad del Estado en la lucha contra la trata de seres humanos y en la colaboración con las organizaciones con experiencia acreditada en la asistencia a las víctimas}

En línea con las recomendaciones del Defensor del Pueblo y del GRETA, y también en consideración con la medida 58 del Plan Integral de lucha contra la trata de mujeres y niñas con fines de explotación sexual, aprobado para el periodo 2015-2018, esta Instrucción establece en su primer punto la figura del Interlocutor Social a nivel nacional en la lucha contra la Trata de Seres Humanos, a partir del cual se establece el punto de contacto permanente entre las Fuerzas y Cuerpos de Seguridad del Estado y las organizaciones con experiencia acreditada en la asistencia a las víctimas de trata.

Las personas que ocupan estos puestos son designadas por las distintas Unidades de la Policía y la Guardia Civil y su principal función es la de facilitar canales de comunicación entre las partes en lo relativo a la detección e identificación de las víctimas.

En todo caso, la cuarta instrucción determina que la identificación de las víctimas se realizara, exclusivamente, por las unidades policiales encargadas, pudiendo siempre comunicarlo a las organizaciones, con el fin de que éstas colaboren aportando información o en lo relativo al desarrollo de la entrevista de identificación. 


\section{3.- Carencias detectadas}

Tal como afirma el Alto Comisionado de las Naciones Unidas para los Derechos Humanos, la consecuencia básica que acarrea la no identificación de una víctima es la completa invisibilización de ella y de su sufrimiento, a lo que se suma la imposibilidad de acceder a cualquiera de los derechos que le corresponden. ${ }^{56}$

De acuerdo con el Centro de Inteligencia contra el Terrorismo y el Crimen Organizado, en 2017 en España, 10.111 personas fueron detectadas como posibles víctimas de trata de personas, al encontrarse en situación de riesgo de explotación sexual. De entre ellas, tan solo 577 fueron formalmente identificadas como víctimas, al tiempo que las condenas por el delito de trata de personas en todas sus modalidades tan solo alcanzaron las 63.57

Estas cifras de identificación son alarmantemente bajas, aún más si se tiene en cuenta que solo se contabilizan las potenciales víctimas de trata con fines de explotación sexual. Se demuestra así la ineficiencia del sistema planteado, ocasionada por la perspectiva criminológica de la que parte, la cual, tal como critica el GRETA en su último Informe, liga en prácticamente todas las ocasiones la protección de la víctima y su voluntad de colaborar con la investigación judicial. ${ }^{58}$

$Y$ es que, a pesar de que el establecimiento de la figura del Interlocutor Social ha supuesto un avance, el mecanismo de identificación formal permanece por completo en manos de la policía, al tiempo que se mantiene la conexión entre identificación y proceso penal.

Así, uno de los graves fallos del sistema español es que la potencial víctima de trata entra en contacto con los efectivos de las Fuerzas y Cuerpos de Seguridad desde el inicio del proceso de identificación. Ello supone un elemento ciertamente disuasorio para todas aquéllas que, de por sí, desconfían de los agentes del orden; al tiempo que se convierte en un obstáculo prácticamente insalvable para las que se encuentran en situación administrativa irregular en nuestro país, ya que temen exponerla y ser deportadas.

Además, tal como afirmó en Francia la Comisión Nacional Consultiva de los Derechos del Hombre, la identificación de las víctimas se ve también dificultada por el hecho de que, en algunas modalidades

\footnotetext{
56 Naciones Unidas, Oficina del Alto Comisionado de los Derechos Humanos. (2014). Los Derechos Humanos y la Trata de Personas, p. 15. Disponible en: https://www.ohchr.org/documents/publications/fs36_sp.pdf

57 Instituto de Derechos Humanos Bartolomé de las Casas. (2019). Trata de seres humanos con fines de explotación sexual: un estudio comparado sobre la detección e identificación de las víctimas, p. 15. Disponible en:

https://clinicajuridicaidhbc.files.wordpress.com/2019/09/informe-clinicaidhbc-tratade-seres-humanos.pdf

58 Group of Experts Against Human Trafficking. (2018). Report concerning the implementation of the Council of Europe Convention on Action against Trafficking in Human Beings by Spain, p. 38. Disponible en: https://rm.coe.int/greta-2018-7-frgesp-en/16808b51e0
} 
de la trata, tales como la explotación orientada a la comisión de hechos delictivos, la víctima se considera a sí misma una delincuente, ${ }^{59}$ temiendo ser tratada como tal por unas autoridades poco familiarizadas con estas realidades.

A todo lo anterior se añade que, tal como manifiesta el GRETA en su último Informe, el umbral de la prueba establecido en España para identificar formalmente a una víctima de trata es muy alto. Ello resulta verdaderamente problemático puesto que todas las medidas de asistencia y protección reconocidas nuestro ordenamiento, giran en torno a la identificación formal; al contrario de lo que ocurre en otros países, donde dependen del uso de conceptos como el de "presunta víctima" o "motivos razonables". 60 Como consecuencia, tanto la identificación formal, como la protección de la víctima de trata, se ven dificultadas por un sistema formalista y poco sensible a la realidad que viven estas personas.

\section{4.- Problemática específica en el caso de los CIE y los CITE}

En nuestro país, los inmigrantes que llegan de manera irregular pueden permanecer hasta 72 horas bajo custodia policial y ser expulsados durante este periodo, sin que la justicia intervenga en absoluto.

Tal como recalca el GRETA en su Informe, tales restricciones temporales, sumadas al hacinamiento en celdas abarrotadas, la falta de servicios de traducción adecuados, y la ausencia de personal especializado, tornan prácticamente imposible la correcta detección de potenciales víctimas de trata en esta primera fase.

En los casos en los que la persona inmigrante no es devuelta durante esas primeras 72 horas, la autoridad fronteriza debe ponerlo en conocimiento del juez para que éste decida si emite una orden de internamiento. De hacerlo, la persona podrá permanecer ingresada hasta un máximo de 60 días en lo que se conoce como Centro de Internamiento de Extranjeros (CIE), o Centro de Estancia Temporal de Inmigrantes (CETI), que encontramos en Ceuta o Melilla.

EI GRETA afirma también que en ninguno de estos contextos se llevan a cabo investigaciones proactivas orientadas a la detección de potenciales víctimas de trata, careciendo el personal de capacitación especializada en la materia, y habiéndose dado casos en los que personas que mostraban claros indicios de ser víctimas de trata,

\footnotetext{
${ }^{59}$ Commission nationale consultative des droits de I'homme. (2015). La lutte contre la traite et l'exploitation des êtres humains. Disponible en:

https://www.cncdh.fr/fr/publications/rapport-sur-la-lutte-contre-la-traite-etlexploitation-des-etreshumains

60 Group of Experts Against Human Trafficking. (2018). Report concerning the implementation of the Council of Europe Convention on Action against Trafficking in Human Beings by Spain, p. 57. Disponible en: https://rm.coe.int/greta-2018-7-frgesp-en/16808b51e0
} 
continuaron retenidas en los centros por motivos de política migratoria. 61

A su vez, de acuerdo con la Oficina del Alto Comisionado de Naciones Unidas para los Derechos Humanos, el principio de no devolución adquiere una gran importancia en relación con el fenómeno de la trata, dado que establece como contraria a derecho internacional cualquier repatriación que implique un riesgo de tortura o tratos 0 penas crueles, inhumanos o degradantes para la persona repatriada. ${ }^{62}$ Tal como se explica en el informe del Defensor del Pueblo, cuando se repatría a una víctima de trata de personas que no ha sido identificada, una vez que ésta llega a su país resulta muy probable que vuelva a caer en las garras de la red criminal, 63 repitiéndose la situación de abuso y traslado forzado, y con ella, los tratos inhumanos y degradantes.

De esta manera, en tanto que España no implemente mecanismos adecuados de identificación en el periodo de las 72 horas iniciales, así como en los Centros de Internamiento, está contraviniendo el derecho internacional, y también su obligación positiva en relación con la lucha contra la trata de seres humanos y la protección de las víctimas.

\section{6.- LA VICTIMIZACIÓN SECUNDARIA Y LAS VÍCTIMAS DE TRATA SERES HUMANOS}

\section{1.- El fenómeno de la victimización secundaria}

Entendiendo victimización primaria como los daños físicos o psicológicos que sufre el sujeto pasivo como consecuencia directa del hecho delictivo; ${ }^{64}$ siguiendo a Soria Verde, la victimización secundaria puede definirse como las consecuencias negativas a nivel psicológico, social y jurídico que se derivan del frustrante choque entre las expectativas de protección y comprensión que tiene la víctima, y la realidad institucional con la que se encuentra. ${ }^{65}$ Este choque aumenta el daño psicológico de la persona, al generarle sentimientos de

\footnotetext{
61 Group of Experts Against Human Trafficking. (2018). Report concerning the implementation of the Council of Europe Convention on Action against Trafficking in Human Beings by Spain, p. 37. Disponible en: https://rm.coe.int/greta-2018-7-frgesp-en/16808b51e0

62 Naciones Unidas, Oficina del Alto Comisionado de los Derechos Humanos. (2014). Los Derechos Humanos y la Trata de Personas, p. 29. Disponible en: https://www.ohchr.org/documents/publications/fs36_sp.pdf 63 Defensor del Pueblo. (2012). La trata de seres humanos en España: víctimas invisibles, p. 179. Disponible en: https://www.defensordelpueblo.es/wpcontent/uploads/2015/05/2012-09-Trata-de-seres-humanos-en-Espa\%C3\%B1av\%C3\%ADctimas-invisibles-ESP.PDF

${ }^{64}$ Fiscal Nacional del Ministerio Público de Chile. (2010). Guía para la evaluación pericial del daño en víctimas de delitos sexuales, p. 37. Disponible en:

https://www.sename.cl/wsename/otros/guia_eval_dan_2010.pdf

65 SORIA VERDE, M.: Psicología y Práctica Jurídica, Ariel S.A., Madrid, 1998.
} 
incomprensión, soledad y desconfianza hacía las autoridades, prolongando el trauma causado por la victimización primaria, ${ }^{66}$ y pudiendo incluso llevar a la cronificación de las secuelas psicopatológicas. ${ }^{67}$

Según Kevin Berril y Gregory Herek, las consecuencias de este fenómeno se agravan aun más en aquellos casos en los que la sociedad responde de forma negativa ante la situación de la víctima por su condición sexual, racial, étnica o religiosa. ${ }^{68}$ Lo mismo ocurre cuando sobre ella pesa algún tipo de estereotipo, al jugar la percepción sobre la inocencia de la persona un papel muy importante en su relación con las autoridades. De esta manera, cuanto más inocente sea percibida la víctima, mayor compasión generará, recibiendo más apoyo entre aquellos que con ella tratan desde las instituciones. ${ }^{69}$

Por último, cabe resaltar que los procesos de victimización secundaria no solo impactan en el bienestar de la víctima, sino también en la eficacia del sistema jurídico penal. $Y$ es que, tal como afirma Sanz-Diez Ulzurrun, resulta mucho más probable que el sujeto pasivo decida cooperar en la investigación y persecución del delito si confía en que el sistema ampara y protege sus derechos. ${ }^{70}$

\section{2.- La victimización secundaria en el proceso de identificación de víctimas de trata}

Cuando trasladamos el fenómeno de la victimización secundaria a la problemática de la trata, ha de tenerse en cuenta que nos hallamos ante personas que se encuentran en una situación mucho más delicada que el común de las víctimas. Así, la víctima de trata suele haber sido engañada y está retenida a través del uso de la fuerza, la coacción y la intimidación, muchas veces en condiciones cercanas a la esclavitud; al tiempo que teme dar a conocer su situación por miedo a posibles represalias contra ella o su familia. A mayor abundamiento, es regularmente trasladada por los tratantes de un lugar a otro del

${ }^{66}$ Gobierno Vasco. (2015). Guía general de buenas prácticas en el trato con víctimas del terrorismo que evite la victimización secundaria, p. 32. Disponible en:

http://www.euskadi.eus/web01-

a2aznscp/eu/k75aWebPublicacionesWar/k75aObtenerPublicacionDigitalServlet?R01

HNoPortal $=$ true\&N_LIBR $=051680 \& N \_E D I C=0001 \& C \_I D I O M=e s \& F O R M A T O=$.pdf

67 Fiscal Nacional del Ministerio Público de Chile. (2010). Guía para la evaluación pericial del daño en víctimas de delitos sexuales, p. 37. Disponible en:

https://www.sename.cl/wsename/otros/guia_eval_dan_2010.pdf

68 KEVIN BERRILL and GREGORY HEREK: Hate Crimes: Confronting Violence Against Lesbians and Gay Men, Sage Publications, California, 1992.

69 ISABEL CORREIRA, PATRICIA AGUILAR and JORGE VALA: "The Effect of Observer's Belief in a Just World and Victim's Innocence on Secondary Victimization, Judgements of Justice and Deservingness, Social Justice Research, 2001, p. 328.

70 SANZ-DIEZ ULZURRUN, M.: "La víctima ante el Derecho. La regulación de la posición jurídica de la víctima en el Derecho internacional, en el Derecho europeo y en el Derecho positivo español", Anuario de Derecho Penal y Ciencias Penales, 2004, p. 303. 
territorio español, con el fin de impedir que entable relaciones estrechas con personas externas a la red, evitando así que genere arraigo con su entorno. ${ }^{71}$

Esta situación, sumada a las experiencias de abuso anteriores, hace que la víctima acabe por sufrir tal degradación física y emocional que, muy posiblemente, y del mismo modo que le ocurre a quienes han padecido torturas, su autoestima y capacidad de reacción emocional acaban por completo anuladas. ${ }^{72}$

A ello han de sumarse los estereotipos, los cuales, tal como advierte la Fiscalía General del Estado, ${ }^{73}$ pueden jugar un papel importante en los procesos de victimización secundaria de estas personas. $Y$ es que, en muchos casos, al esperar los agentes que las víctimas, en especial las mujeres, presenten determinados comportamientos, cuando ello no ocurre, comienzan a cuestionar su condición de víctimas. ${ }^{74}$ Esta reacción al incumplimiento del rol impuesto hace que la víctima se sienta rebatida, incomprendida y juzgada, lo que sin duda agrava su proceso de victimización secundaria.

Partiendo de esta base, y del hecho de que el grado de trauma de un individuo no siempre es evidente, ${ }^{75}$ idealmente todo contacto que se mantuviera con una persona que ha sido, o parece haber sido, víctima de trata, habría de desarrollarse con suma delicadeza, evitando cualquier tipo de elemento estresor y tratando en todo momento de generar un espacio reconfortante y de seguridad.

Esta necesidad de confianza y seguridad se torna aún más acuciante durante los momentos de detección e identificación, especialmente en los casos de víctimas no nacionales, ya que éste puede ser su primer contacto con las instituciones españolas.

Sin embargo, tal como se ha relatado anteriormente, en el sistema que opera actualmente en nuestro país, son miembros de las Fuerzas y Cuerpos de Seguridad quienes tratan con la víctima a lo largo de todo el proceso de identificación, lo que supone un elemento

71 Red Española Contra la Trata de Personas. (2008). Guía Básica para la identificación, derivación y protección de las personas víctimas de trata con fines de explotación sexual, pp. 19 - 20. Disponible en:

file://C:/Users/itzin/Downloads/Guia_Basica_Identificacion.pdf

72 Fiscalía General del Estado. (2019). Memoria elevada al Gobierno de S. M., p. 1239. Disponible en:

https://www.fiscal.es/memorias/memoria2019/FISCALIA_SITE/index.html

73 Fiscalía General del Estado. (2019). Memoria elevada al Gobierno de S.M., p. 22. Disponible en:

https://www.fiscal.es/memorias/memoria2019/FISCALIA_SITE/index.html

74 Group of Experts Against Human Trafficking. (2018). Report concerning the implementation of the Council of Europe Convention on Action against Trafficking in Human Beings by Spain. Disponible en: https://rm.coe.int/greta-2018-7-frg-espen/16808b51e0

75 World Health Organization. (2003). Ethical and safety recommendations for interviewing trafficked women, p. 5. Disponible en:

https://apps.who.int/iris/handle/10665/42765 
estresor para la gran mayoría de ellas, en especial las que se encuentran en situación irregular en España, al estar la figura de la policía ligada indisolublemente con la idea de deportación. ${ }^{76}$

A mayor abundamiento, a pesar de que la Red Española Contra la Trata de Personas deja claro en su Guía Básica para la identificación de las víctimas, que para reducir el fenómeno de la victimización secundaria resulta esencial generar un clima de confianza ya desde los primeros momentos, ${ }^{77}$ el Protocolo Marco de Protección a las Víctimas de trata de seres humanos, anteriormente explicado, deja bastante que desear en este aspecto.

Así, tal como se expuso, de acuerdo con este Protocolo, la generación de un ambiente adecuado a las circunstancias de la persona, o la asistencia jurídica durante la entrevista personal, son cuestiones que solo serán aseguradas en la medida de lo posible. Esta redacción no solo no entra en mandato específico alguno, sino que abre la puerta a la discrecionalidad de las autoridades en un momento que, por lo general, resulta traumático y muy confuso para la mayoría de las víctimas.

A pesar de la expresa recomendación de la Organización Mundial de la Salud, ${ }^{78}$ no se recogen tampoco los supuestos en los que las entrevistas deben considerarse pospuestas, por ejemplo, cuando la víctima se encuentra demasiado nerviosa para continuar, dejándose este tipo de decisiones de nuevo en manos de los concretos agentes y su discrecionalidad.

Tampoco se prevé formalmente, ni se establecen mecanismos que promuevan, la presencia de miembros de asociaciones especializadas en esta primera etapa, a pesar de que su compañía resultaría idónea para dar confianza a la víctima y, al mismo tiempo, velar porque sus derechos no sucumban ante los intereses políticocriminales o de control migratorio del Estado.

Y es que, si ya en el común de las investigaciones y los procesos penales la sensibilidad de las víctimas no es especialmente tenida en cuenta, cuando nos encontramos ante personas que en muchos casos residen en nuestro país de forma irregular, y que probablemente son conocedoras de información útil para desarticular redes de traficantes de seres humanos, los intereses político-criminales y de control de la inmigración ilegal pueden adquirir una posición preponderante en cualquier punto del proceso.

\footnotetext{
76 World Health Organization. (2003). Ethical and safety recommendations for interviewing trafficked women, p. 7. Disponible en:

https://apps.who.int/iris/handle/10665/42765

77 Red Española Contra la Trata de Personas. (2008). Guía Básica para la identificación, derivación y protección de las personas víctimas de trata con fines de explotación sexual, p. 22. Disponible en:

file:///C:/Users/itzin/Downloads/Guia_Basica_Identificacion.pdf

78 World Health Organization. (2003). Ethical and safety recommendations for interviewing trafficked women, p. 5. Disponible en:

https://apps.who.int/iris/handle/10665/42765
} 
Con todo, el mecanismo de identificación de víctimas de trata que opera actualmente en España no es suficientemente eficaz a la hora de reducir los elementos estresores del entorno y, con ello, los procesos de victimización secundaria. Ello aleja a nuestro país de la perspectiva de derechos humanos que, siguiendo los mandatos de las instancias internacionales, debería caracterizar todo nuestro sistema de lucha contra esta problemática.

Sumado a ello, al no generarse un clima de seguridad, no se incentiva la confianza de la víctima en las instituciones, lo que resulta ineficaz también desde la perspectiva pragmática, ya que resulta mucho más probable que la víctima decida cooperar con la investigación y persecución del delito de trata si confía en un sistema que la ampara y la comprende. La ineficacia del sistema actual queda demostrada por las cifras, habiendo habido tan solo 86 sentencias condenatorias por el delito de trata de seres humanos durante el periodo de 2013 a 2018. ${ }^{79}$

Así, la mejora del procedimiento de identificación de víctimas de trata que opera en España actualmente no solo es exigencia del enfoque de derechos humanos que nuestro país se ha comprometido a implementar, sino también del pragmatismo y la eficacia en la persecución del delito de trata de seres humanos.

Por todo ello, España debería acabar con la discrecionalidad presente en este proceso, estableciendo medidas específicamente orientadas a minimizar, de no ser posible evitar, los procesos de victimización secundaria que sufren estas personas.

\section{7.- ¿CÓMO LO HACEN OTROS PAÍSES EUROPEOS? RECOMENDACIONES PARA ESPAÑA}

Este estudio bebe principalmente del Informe de derecho comparado llevado a cabo por el Instituto de Derechos Humanos Bartolomé de las Casas, en su clínica jurídica de 2019, en colaboración con la Asociación Trabe y la Fundación Pombo, ${ }^{80}$ así como de la investigación del Alto Comisionado de las Naciones Unidas para los Refugiados sobre el modelo noruego de identificación y protección de víctimas de trata. ${ }^{81}$ Para el análisis comparado de la legislación penal

79 Fiscalía General del Estado. (2019). Memoria elevada al Gobierno de S.M. Disponible en:

https://www.fiscal.es/memorias/memoria2019/FISCALIA_SITE/index.html

80 Instituto de Derechos Humanos Bartolomé de las Casas. (2019). Trata de seres humanos con fines de explotación sexual: un estudio comparado sobre la detección e identificación de las víctimas, pp. 21-106. Disponible en:

https://clinicajuridicaidhbc.files.wordpress.com/2019/09/informe-clinicaidhbc-tratade-seres-humanos.pdf

81 Alto Comisionado de las Naciones Unidas para los Refugiados. (2009). Identificación y derivación de las personas víctimas de trata a los procedimientos para la determinación de las necesidades de protección internacional, pp. 17 - 19. Disponible en: 
se hará uso de la Memoria de la Fiscalía General del Estado del año 2019.82

\section{1.- Mecanismos implementados en otros países europeos}

\subsection{1.- Alemania}

En este país, las asociaciones especializadas en trata de personas han firmado acuerdos formales de colaboración con el Estado. Gracias a ello, las potenciales víctimas tienen derecho a un intérprete de su lengua materna, y también a ser acompañadas por un representante de estas asociaciones a todas y cada una de las entrevistas que hayan de realizarse para su identificación.

Sumado a ello, y para minimizar el obstáculo que para muchas supone su residencia irregular en el país, las autoridades deben otorgar un permiso de residencia temporal a las víctimas de trata.

Por último, el Código Penal alemán prevé en su artículo 232 b) la tipificación del trabajo forzoso, delito de resultado, quedando así disociada de la trata de seres humanos, delito antecedente recogido en el artículo 232.

\subsection{2.- Bélgica}

En el reino belga, cuando una víctima es formalmente identificada, debe ser derivada a uno de los tres centros especializados que colaboran por cauces formales con el Estado, y que le procurarán alojamiento, apoyo médico y psicológico, asistencia jurídica y administrativa.

\subsection{3.- Francia}

En la República francesa es la trata con fines de explotación sexual la que se persigue con mayor contundencia, estando a su vez indisociablemente ligada a la prostitución, frente a la que Francia ha adoptado una postura abolicionista.

La legislación contempla la concesión de un permiso de residencia temporal a todas aquellas víctimas en situación irregular con la única condición de que se comprometan a salir de la prostitución y a tratar de integrarse social y profesionalmente.

De esta forma, el Estado francés no liga la concesión de residencia con la cooperación de la víctima de trata con fines de explotación sexual; a su vez, en caso de que ésta decidiese denunciar

https://www.refworld.org/cgi-

bin/texis/vtx/rwmain/opendocpdf.pdf?reldoc=y\&docid $=4$ af98bfe2

82 Fiscalía General del Estado. (2019). Memoria elevada al Gobierno de S.M. Disponible en:

https://www.fiscal.es/memorias/memoria2019/FISCALIA_SITE/index.html 
o testificar, adquiriría automáticamente derecho a un permiso de residencia temporal.

Al mismo tiempo, y como herramienta eficaz para permitir la comprensión y generar un clima de confianza, Francia ha introducido la figura del mediador cultural, quien interviene en cada etapa del proceso de identificación, explicando a las víctimas sus derechos y ayudándolas a consolidar su discurso. A su vez, sus servicios pueden ser solicitados para promover el aprendizaje entre los equipos sociales de las distintas representaciones culturales, lo que resulta muy útil a la hora de comprender a las distintas víctimas y sus situaciones.

En este país la legislación penal también separa el delito de trata de seres humanos y los tipos de esclavitud, explotación de un esclavo, imposición de condiciones laborales o de alojamiento contrarias a la dignidad del individuo.

\subsection{4.- Italia}

Italia cuenta con uno de los modelos más avanzados del continente europeo e internacional en lo que a protección de las víctimas de trata se refiere, el cual permitió que, de las 8.277 víctimas potenciales detectadas en 2016, 6.599 fueran formalmente identificadas.

Dentro de su sistema de identificación ha de distinguirse entre: identificación preliminar definida, destinada a dar un primer análisis de la situación y realizada en la primera toma de contacto que se tiene con la potencial víctima, siempre a partir de preguntas "apropiadas" y "relevantes", preestablecidas en un modelo; e identificación formal, que gravita en torno a entrevistas en profundidad entre un representante de las organizaciones especializadas y la presunta víctima, y la recopilación de cualquier otra información que permita la verificación de sus relatos.

Sumado a tales esfuerzos por crear un clima de confianza, el proceso de identificación formal solo podrá llevarse a cabo una vez que la potencial víctima haya recibido información acerca de la entrevista y las alternativas a la misma. Además, está estipulado formalmente que dicha entrevista no podrá tener lugar si la persona está angustiada, ansiosa, deprimida o quiere llorar; es hostil o agresiva, pide que se posponga la entrevista o busca consejo legal. Así, en cualquiera de estas circunstancias, la víctima deberá ser beneficiaria de un periodo de recuperación y reflexión, el cual no depende de su identificación formal.

El sistema italiano contempla también la concesión de un permiso de residencia a aquellas víctimas en situación irregular cuya vida corra peligro, bien por las declaraciones formuladas en el curso de un proceso penal, o por la mera decisión de acabar con la situación de explotación, sin que sea necesaria la denuncia. 
Por último, el Código Penal italiano regula en su artículo 600 los supuestos de servidumbre y esclavitud, de nuevo disociándolos de la trata de personas, contenida en el artículo 601.

\subsection{5.- Países Bajos}

En este territorio también tiene lugar una cooperación formal con un concreto centro especializado, al tiempo que la persona puede acceder al periodo de reflexión desde el momento en que es detectada como víctima potencial, no siendo precisa la identificación formal.

\subsection{6.- Reino Unido}

En el Reino Unido la identificación formal de las víctimas se determina a partir de la existencia de motivos razonables.

Al mismo tiempo, resulta significativo que las empresas deben realizar la denominada Declaración de esclavitud y trata de personas, a partir de la que detallan las medidas que adoptan para asegurar que en su cadena de suministro no tiene lugar situación alguna de este tipo.

\subsection{7.- Noruega}

En este país la cooperación con las organizaciones especializadas también se encuentra formalizada, a través de la Unidad de Coordinación Nacional (KOM) que agrupa a representantes de dichas organizaciones y de organismos gubernamentales, estando administrada por la Dirección Nacional de Policía.

La KOM distingue entre identificación de posibles víctimas de trata y verificación de las víctimas, poniendo todos los servicios de asistencia a disposición de todas, independientemente del momento del proceso en el que se encuentren.

\section{2.- Recomendaciones para España}

\subsection{1.- Humanización del proceso de identificación}

Como bien explican Santos Martín y Martín Ríos, una de las exigencias que derivan de la aplicación de un enfoque de derechos humanos a la problemática de la trata es que las autoridades han de buscar en todo momento el equilibrio entre los derechos de la víctima y el resto de los derechos procesales.

Tal como ha recalcado la Fiscalía General del Estado, para acercar el sistema de identificación de víctimas de trata a la realidad que viven estas personas, España debería acabar con la discrecionalidad presente en el proceso de identificación, estableciendo 
medidas específicamente orientadas a minimizar, de no ser posible evitar, los procesos de victimización secundaria. ${ }^{83}$

Siguiendo el ejemplo de Italia y las recomendaciones de la Organización Mundial de la Salud, ${ }^{84}$ una primera medida podría ser que la entrevista en profundidad la llevase a cabo un psicólogo especializado, en vez de un agente de las Fuerzas y Cuerpos de Seguridad el cual, por instruido que esté, no deja de ser una figura de autoridad.

También podría recogerse como exigencia que la potencial víctima estuviese acompañada por un representante de las asociaciones especializadas ya desde esta primera fase, tal como ocurre en Alemania.

Siguiendo a Francia, en nuestro país debería además instaurarse la figura del mediador cultural, ya que podría suponer un verdadero salto cualitativo en lo que al bienestar y comprensión de la víctima se refiere. $Y$ es que, al estar este profesional entrenado para entender los distintos contextos y bagajes culturales, elementos que sin duda influyen en las circunstancias de una persona y en cómo reacciona a los sucesos que le ocurren, su presencia podría lograr que las potenciales víctimas percibiesen una mayor sensibilidad y apoyo por parte de las instituciones, mostrándose así más coherentes en su discurso y también más colaborativas con las autoridades.

A su vez, a través de cursos de formación, el mediador cultural podría instruir al personal que trabaja con las víctimas de trata acerca de los sentimientos y realidades de estas personas, ayudando así a acabar con los estereotipos y prejuicios que pesan sobre ellas.

La implementación de estas medidas resulta aún más necesaria en los CIE y los CITE, dado que las restricciones de tiempo, sumadas a la ausencia de protocolos capaces de fomentar la proactividad en la detección de potenciales víctimas, hacen que la presencia de psicólogos especializados, representantes de asociaciones de lucha contra la trata y mediadores culturales resulte aun más necesaria, al ser éstos los que cuentan con acreditada capacidad, e interés, para detectar y socorrer a las víctimas de trata que se encuentran internadas en los centros.

\subsection{2. - Ofrecimiento del periodo de restablecimiento y reflexión a víctimas que aún no han sido formalmente identificadas}

Al contrario que en países como Italia, Países Bajos o Noruega, en España el disfrute de este periodo y sus beneficios asistenciales sólo se ofrece a víctimas extranjeras que ya hayan sido formalmente identificadas. El problema está en que, como ya se ha explicado, para

${ }^{83}$ Fiscalía General del Estado. (2019). Memoria elevada al Gobierno de S.M., p. 21. Disponible en:

https://www.fiscal.es/memorias/memoria2019/FISCALIA_SITE/index.html

84 World Health Organization. (2003). Ethical and safety recommendations for interviewing trafficked women, p. 10. Disponible en:

https://apps.who.int/iris/handle/10665/42765 
ser identificadas primero han de ser entrevistadas en profundidad por miembros de las Fuerzas y Cuerpos de Seguridad, habiendo de conducir esta entrevista con atino, algo para lo que muchas pueden sentirse incapaces en un primer momento.

No hemos de olvidar que tratamos con personas que no cuentan con arraigo en nuestro país y que, en la mayoría de las ocasiones, no han tenido contacto previo con las instituciones españolas, a lo que se suma el temor que les genera que la irregularidad de su situación sea descubierta.

Llegamos así a una situación circular en la que la víctima, al no estar formalmente identificada, no tiene acceso al periodo de reflexión y, por tanto, a los derechos de asistencia que le acompañan, lo que redunda en su bienestar, pero también en su disposición y capacidad de colaborar con la investigación.

Por ende, tanto en interés de la víctima, como del proceso penal, el Estado español debería acabar con este círculo vicioso, siguiendo el ejemplo de sus vecinos y ofreciendo el periodo de reflexión, y los servicios de asistencia que lo acompañan, a todas aquellas personas que presenten indicios de ser víctimas de trata.

Otra opción sería elegir el modelo normativo italiano, en el que el ofrecimiento del periodo de reflexión está en principio reservado a víctimas ya formalmente identificadas, pero se ofrece en aquellos casos en los que la víctima potencial se muestra muy hostil o agresiva en el momento en que se va a llevar a cabo la entrevista en profundidad, así como si presenta signos de depresión, ansiedad o angustia, sentimientos que pueden impedir que conduzca con normalidad y atino la entrevista.

7.2.3.- Ampliación de las situaciones en las que se otorga a la víctima un permiso de residencia

Tal como explican Santos Martín y Martín Ríos en su obra, la concesión de permisos de residencia, temporales o permanentes, a las víctimas de trata constituye otra manera que tienen los Estado de respetar los derechos humanos de estas personas. ${ }^{85}$

Siguiendo este razonamiento, países como Alemania estipulan la concesión automática del permiso de residencia una vez que la víctima ha decidido cooperar con las autoridades, evitando así cualquier arbitrariedad institucional. Por su parte, Francia, si bien tan solo en relación con las víctimas de trata con fines de explotación sexual, prevé la concesión de residencia a toda víctima que decida desvincularse de la red de trata, aun si no quiere colaborar con la investigación.

El establecimiento de esta última medida podría suponer un avance en la lucha contra la trata en España, dado que, si a la víctima se le otorga un permiso de residencia que no se encuentra supeditado

85 SANTOS MARTÍN, J. y MARTÍN RÍOS, P.: La tutela de la víctima de trata: una perspectiva penal, procesal e internacional, Bosch Editor, Barcelona, 2019, p. 192. 
a su colaboración con las autoridades, acompañado de un cierto apoyo institucional para su integración, le resultará mucho más fácil generar arraigo y redes sociales en nuestro país; lo que con mucha probabilidad redundará en un aumento de su sensación de seguridad y confianza, resultando entonces mucho más probable que se preste a colaborar con las autoridades en la persecución del delito.

$Y$ es que, hemos de recordar en todo momento que, tal como refiere la Fiscalía General del Estado, estamos ante personas extremadamente vulnerables, que se sienten en muchos casos por completo anuladas, llegando incluso a perder conciencia de su propia situación. ${ }^{86}$ Es por ello que, la forma de respetar sus derechos humanos, así como de fomentar su colaboración con las investigaciones policiales, pasa por permitirles residir legalmente en España durante un periodo de tiempo, de forma que tengan la oportunidad de recuperarse de la explotación sufrida, mejorando así su autoestima y, con ello, su capacidad de enfrentarse a sus victimarios.

\subsection{4.- Tipificación de los delitos de esclavitud, servidumbre y trabajo} forzoso

Tal como se ha expuesto, el ordenamiento penal español no tipifica las formas de explotación, ya sea laboral o sexual, a las que pretende dar lugar el delito de trata de personas. De esta forma, en España una persona puede ser víctima de trata con fines de esclavitud, servidumbre o trabajo forzoso, pero no puede ser víctima de esclavitud, servidumbre o trabajo forzoso, lo que resulta ilógico e ineficaz en la lucha contra la trata.

A su vez, los delitos contra los derechos de los trabajadores no son equiparables a las conductas recogidas en el artículo 177 Bis, por lo que, en aras de cumplir con las exigencias del derecho internacional, expresas desde el año 2014, y siguiendo el ejemplo de países como Alemania, Italia o Francia, España debería tipificar los supuestos de esclavitud, servidumbre y trabajo forzoso.

\subsection{5.- Elaboración de una Ley integral contra la trata de personas}

La propia Organización de Naciones Unidas ha elaborado un modelo de Ley integral contra la trata de personas, donde se recoge desde la tutela penal, hasta la identificación de la víctima, pasando por los mecanismos de prevención. 87

La importancia de la aprobación de una Ley integral radica en que, al ser norma, resultaría de obligado cumplimiento, al contrario

${ }^{86}$ Fiscalía General del Estado. (2019). Memoria elevada al Gobierno de S.M., p. 21. Disponible en:

https://www.fiscal.es/memorias/memoria2019/FISCALIA_SITE/index.html

87 Oficina de las Naciones Unidas contra la Droga y el Delito. (2010). Ley modelo contra la trata de personas. Disponible en:

https://www.unodc.org/documents/human-trafficking/TIP-Model-Law-Spanish.pdf 
que los planes de actuación y protocolos, de carácter meramente orientativo.

A su vez, contaría con una labor didáctica, acercando la realidad de la trata a una sociedad hoy en día ciertamente ajena a ella, lo que ayudaría a erradicar los prejuicios y estereotipos que pesan sobre estas víctimas.

De este modo, la elaboración de una norma que unifique y aporte coherencia a las estrategias de lucha contra la trata, consolidando los objetivos comunes y la perspectiva de respeto a los derechos humanos, podría suponer un verdadero salto cualitativo, tanto en lo relativo a la protección y bienestar de víctimas, como en la persecución misma del delito.

Además, una ley integral bien elaborada permitiría combatir todas las modalidades de trata de personas con contundencia, y no solo aquella con fines de explotación sexual; al tiempo que las protecciones recogidas en el artículo 59 Bis LOEX, en la actualidad contempladas exclusivamente para individuos no nacionales de un Estado Miembro de la Unión Europea, podrían ampliarse a todas las víctimas, independientemente de su lugar de procedencia.

En esta norma podrían también formalizarse, tal como se ha hecho en Alemania, Bélgica, Países Bajos o Noruega, las relaciones entre las instituciones estatales y las asociaciones especializadas, otorgando a estas últimas su propio papel, exigible y ajeno a discrecionalidad de cualquier clase.

Por último, sería muy útil que, siguiendo el ejemplo de Reino Unido, esta ley estableciese la obligación de todas las empresas en España de desarrollar una Declaración de esclavitud y trata de personas, a través de la cual tuviesen que detallar las medidas y procedimientos que llevan a cabo para cerciorarse de que, en ningún sector de la empresa, o de la cadena de suministro, tienen lugar situaciones de este tipo.

\section{8.- CONCLUSIONES}

En el presente trabajo he tratado de dar una visión pormenorizada de la normativa que opera actualmente en España en relación con el fenómeno de la trata de seres humanos. A tal fin, he partido de una descripción del fenómeno y sus diferencias respecto de otras realidades, tales como el tráfico ilícito de personas o la prostitución; al tiempo que he resaltado la obligación positiva del Estado español de proteger a las víctimas de la mejor manera posible.

Posteriormente, y con el fin de determinar las obligaciones a las que está sujeto nuestro país en esta materia, hice un recorrido por la legislación internacional y regional más relevante, mostrando cómo, con el transcurso del tiempo, la perspectiva criminocéntrica tradicional ha ido avanzando hacía aproximaciones más victimocéntricas, a través de las que las instituciones tratan de asegurar el bienestar de las víctimas y el respeto a los derechos humanos. 
Después profundicé en la legislación española, desarrollando un minucioso análisis del tipo básico del delito de trata de seres humanos; al tiempo que de otras normas que resultan de aplicación a esta realidad, tales como la LOEX o el Estatuto de la víctima del delito. Sobre esta base, ha sido posible enumerar las carencias más relevantes del marco legislativo español en esta materia, resaltando con ello la necesariedad de reformar aspectos como la ausencia de tipificación de los delitos finales que suceden al fenómeno de la trata, entendido como delito antecedente. Y es que, dicha ausencia colisiona frontalmente con las obligaciones internacionales adquiridas por España, y también con el sentido común.

En pos de mostrar las debilidades de la normativa española en lo relativo a la prevención de los procesos de victimización secundaria, y tomando como referencia el mecanismo de identificación, queda expuesto cómo, además de no resultar éste eficaz a la hora de identificar a las víctimas de trata, muchos de los elementos que lo componen tampoco resultan adecuados, al no ser suficientemente sensibles a la realidad que viven estas personas. Así, cuestiones como el contacto constante con agentes policiales durante el proceso de identificación, no contando con el apoyo formal de miembros de asociaciones especializadas, 0 de mediadores culturales, puede sin duda contribuir a incrementar el estrés y la confusión de la víctima, aumentando su sufrimiento y su proceso de victimización secundaria. La adopción de medidas como las que se proponen no solo redunda en el bienestar de estas personas, sino también en el funcionamiento y la eficacia del sistema jurídico penal, dado que, mientras menos segura y amparada por las instituciones se sienta la víctima, menor será su predisposición para colaborar con la investigación y persecución del delito de trata.

Por último, y con el fin de cruzar la barrera de la mera descripción crítica, en la parte final de este trabajo, me aproximé a un estudio comparado de la normativa existente en siete países europeos en relación con esta problemática y, en concreto, con la protección de sus víctimas. Sobre esta base, he procedido a presentar cinco recomendaciones, que podrían resultar de utilidad a la hora de acercar España a sus compromisos internacionales; al tiempo que para mejorar la situación de las víctimas $y$, en consecuencia, también la funcionalidad del sistema jurídico penal español.

Así, la inclusión formal en el proceso de identificación de representantes de asociaciones especializadas, 0 de mediadores culturales, resultaría muy útil a la hora de humanizar el mecanismo de identificación de víctimas de trata, especialmente dentro de los CIE y los CITE, al acercarlo a la realidad de estas personas, pudiendo con ello lograr que se sientan más seguras y que confíen en las instituciones españolas.

A su vez, el ofrecer a las víctimas potenciales provenientes de Estados extracomunitarios el periodo de restablecimiento y reflexión, acabaría con el círculo vicioso en el cual, al no estar la víctima 
formalmente identificada, no cuenta con apoyo institucional alguno para salir de la delicada situación en la que se encuentra, al tiempo que vive en un riesgo constante de deportación.

En línea con la idea de deportación, otro elemento que sin duda mejoraría el bienestar de estas personas, además de fomentar su arraigo, y con ello su capacidad de enfrentarse a los victimarios, sería la concesión de un permiso de residencia automático en aquellos casos en los que diesen el paso de desvincularse de la red de trata. Ello supondría, sin duda, un cambio de perspectiva, pasando de una visión puramente criminológica, en la que la víctima solo puede obtener un permiso de residencia en caso de que decida colaborar con la investigación penal, o de darse circunstancias excepcionales, a un enfoque claramente victimológico, en el que el bienestar y la recuperación de la víctima son antepuestos a los intereses puramente político-criminales y de control de la inmigración.

Respecto a la vertiente legislativa, el Estado español debe tipificar los delitos que suceden a la trata de personas, no solo por mandato del Derecho internacional, sino porque, tal y como ha recalcado la Fiscalía General del Estado, la forma en que se persigue el delito final afecta a la eficacia en la persecución el delito antecedente. A su vez, debería elaborarse una ley integral al objeto de combatir con similar contundencia las diferentes modalidades de trata, ampliando las protecciones establecidas en el ordenamiento a todas las víctimas nacionales y extranjeras, independientemente de si provienen de un Estado Miembro, y acabando con la multiplicidad de normas.

Estas recomendaciones podrían resultar de utilidad a la hora de acercar al Estado español a sus compromisos de respeto a los derechos humanos de las víctimas de trata, y también al cumplimiento de sus obligaciones positivas en el plano internacional.

La víctima de trata es una víctima invisible, que se enfrenta al maltrato de sus victimarios, pero también al rechazo de la sociedad, dado que sobre ella pesan multitud de prejuicios y estereotipos, anquilosados en el pasado, siendo el desarrollo de un sistema sensible a sus necesidades una exigencia para todo aquel Estado que pretenda entrar en la categoría de "Estado del bienestar".

\section{9.- REFERENCIAS}

\section{1.- Bibliografía}

AGUILA LARA, M.: "La Trata de Seres Humanos con Fines de Explotación Sexual", Revista Internacional de Pensamiento Político, 2014, 399 - 423.

DÍAZ BARRADO, C.: "La lucha contra la trata de seres humanos en la Unión Europea: los componentes para una política propia", Revista de Derecho Comunitario Europeo, 2017, 461-498.

ESCRIBANO ÚBEDA-PORTUGUÉS, J.: "Evolución y desarrollos normativos en el derecho internacional y europeo en la lucha 
contra la trata de personas y el tráfico ilícito de migrantes", Nova et Vetera, 2011, $133-150$.

GUTIERREZ, C., CORONEL, E. y PEREZ, C.: "Revisión teórica del concepto de victimización secundaria", Liberabit, 2009, 49 - 58.

ISABEL CORREIRA, PATRICIA AGUILAR and JORGE VALA: "The Effect of Observer's Belief in a Just World and Victim's Innocence on Secondary Victimization, Judgements of Justice and Deservingness, Social Justice Research, 2001, 327-342.

KEVIN BERRIL and GREGORY HEREK: Hate Crimes: Confronting Violence Against Lesbians and Gay Men, Sage Publications, California, 1992.

LÓPEZ RODRIGUEZ, J. y ARRIETA IDIKEZ, F.: "La trata de seres humanos con fines de explotación laboral en la legislación española", Revista cuatrimestral de las Facultades de Derecho y Ciencias Económicas y Empresariales, 2019, 2 - 24.

MARTOS NUÑEZ, J.: "El delito de trata de seres humanos: análisis del artículo 177 Bis del Código Penal", Estudios Penales y Criminológicos, 2012, 97 - 130.

POMARES CINTAS, E.: El Derecho Penal ante la explotación laboral y otras formas de violencia en el trabajo, Tirant lo Blanch, Valencia, 2013.

SANTOS MARTÍN, J. y MARTÍN RÍOS, P.: La tutela de la víctima de trata: una perspectiva penal, procesal e internacional, Bosch Editor, Barcelona, 2019.

SANZ-DIEZ ULZURRUN, M.: "La víctima ante el Derecho. La regulación de la posición jurídica de la víctima en el Derecho internacional, en el Derecho europeo y en el Derecho positivo español", Anuario de Derecho Penal y Ciencias Penales, 2004, 220 - 309.

SORIA VERDE, M.: Psicología y Práctica Jurídica, Ariel S.A., Madrid, 1998.

VILLACAMPA ESTIARTE, C.: "El delito de trata de personas: análisis del nuevo artículo 177 Bis del Código Penal desde la óptica del cumplimiento de compromisos internacionales de incriminación", Anuario da Facultade de Dereito da Universidade da Coruña, 2010, $819-865$.

VILLACAMPA ESTIARTE, C.: "La nueva Directiva europea relativa a la prevención y la lucha contra la trata de seres humanos y a la protección de las víctimas", Revista Electrónica de Ciencia Penal y Criminología, 2011, 1 - 52.

\section{2.- Fuentes normativas españolas}

Instrumento de Ratificación del Protocolo para prevenir, reprimir y sancionar la trata de personas, especialmente mujeres y niños, que complementa la Convención de las Naciones Unidas contra la delincuencia organizada transnacional, hecho en Nueva York el 15 de noviembre de 2000. Disponible en: https://www.boe.es/diario boe/txt.php?id=BOE-A-2003-22719 
Instrumento de Ratificación del Convenio del Consejo de Europa sobre la lucha contra la trata de seres humanos (Convenio no $197 \mathrm{del}$ Consejo de Europa), hecho en Varsovia el 16 de mayo de 2005. Disponible en: https://www.boe.es/diario boe/txt.php?id=BOEA-2009-14405

Ley Orgánica 10/1995, de 23 de noviembre, del Código Penal. Disponible en: https://www.boe.es/buscar/act.php?id=BOE-A1995-25444

Ley Orgánica 4/2000, de 11 de enero, sobre derechos y libertades de los extranjeros en España y su integración social. Disponible en: https://www.boe.es/buscar/act.php?id=BOE-A-2000-544

\section{3.- Fuentes normativas europeas e internacionales}

Directiva 2004/81/CE del Consejo de 29 de abril de 2004, relativa a la expedición de un permiso de residencia a nacionales de terceros países que sean víctimas de la trata de seres humanos o hayan sido objeto de una acción de ayuda a la inmigración ilegal, que cooperen con las autoridades competentes (Diario Oficial de la Unión Europea núm. 261, de 6 de agosto de 2004). Disponible en: https://www.boe.es/doue/2004/261/L00019-00023.pdf

Protocolo de 2014 relativo al Convenio sobre el trabajo forzoso, Ginebra, 28 de mayo de 2014. Disponible en: https://www.ilo.org/dyn/normlex/es/f?p=NORMLEXPUB:12100: 0::NO::P12100 ILO CODE:P029

Protocolo para prevenir, reprimir y sancionar la trata de personas, especialmente mujeres y niños, que complementa la Convención de las Naciones Unidas contra la Delincuencia Organizada Transnacional, Nueva York, 2000. Disponible en: https://www.ohchr.org/documents/professionalinterest/protocol traffickinginpersons sp.pdf

Convención de las Naciones Unidas contra la delincuencia organizada transnacional y sus protocolos, Nueva York, 2004. Disponible en: https://www.unodc.org/documents/treaties/UNTOC/Publication s/TOC\%20Convention/TOCebook-s.pdf

Convenio del Consejo de Europa sobre la lucha contra la trata de seres humanos, Varsovia, 16 de mayo de 2005. Disponible en: https://rm.coe.int/CoERMPublicCommonSearchServices/Display DCTMContent?documentId $=090000168064898 \mathrm{~d}$

Directiva 2011/36/UE del Parlamento Europeo y del Consejo, de 5 abril de 2011 , relativa a la prevención y lucha contra la trata de seres humanos y a la protección de las víctimas y por la que se sustituye la Decisión marco 2002/629/JAI del Consejo (Diario Oficial de la Unión Europea núm. 101, de 15 de abril de 2011). Disponible en: https://eur-lex.europa.eu/legalcontent/ES/TXT/PDF/?uri=CELEX:32011L0036\&from=en 


\section{4.- Fuentes jurisprudenciales}

Sentencia del Tribunal Supremo núm. STS 188/2016, 4 de marzo de 2016.

Sentencia del Tribunal Supremo núm. 378/2011, de 17 de mayo de 2011.

Sentencia del Tribunal Europeo de Derechos Humanos (Sección $1^{\text {a }}$ ). Ranstsev contra Chipre y Rusia, 7 enero de 2010.

Sentencia del Tribunal Europeo de Derechos Humanos (Sección 2a). Siliadin contra Francia, 26 octubre de 2005.

\section{5.- Protocolos, informes y estudios oficiales}

Commission nationale consultative des droits de l'homme. (2015). La lutte contre la traite et l'exploitation des êtres humains. Disponible en: https://www.cncdh.fr/fr/publications/rapportsur-la-lutte-contre-la-traite-et-lexploitation-des-etreshumains

Consejo General del Poder Judicial. (2018). Guía de Criterios de Actuación Judicial Frente a la Trata de Seres Humanos. Disponible en: http://www.poderjudicial.es/cgpj/es/PoderJudicial/En-Portada/EI-CGPJ-presenta-una-Guia-de-criterios-deactuacion-judicial-para-detectar-e-investigar-la-trata-de-sereshumanos-con-fines-de-explotacion

Defensor del Pueblo. (2012). La trata de seres humanos en España: víctimas invisibles. Disponible en:

https://www.defensordelpueblo.es/wpcontent/uploads/2015/05/2012-09-Trata-de-seres-humanosen-Espa\%C3\%B1a-v\%C3\%ADctimas-invisibles-ESP.PDF

Fiscal Nacional del Ministerio Público de Chile. (2010). Guía para la evaluación pericial del daño en víctimas de delitos sexuales. Disponible en:

https://www.sename.cl/wsename/otros/guia eval dan 2010.pdf

Fiscalía General del Estado. (2019). Memoria elevada al Gobierno de S.M. Disponible en:

https://www.fiscal.es/memorias/memoria2019/FISCALIA SITE/ index.html

Gobierno Vasco. (2015). Guía general de buenas prácticas en el trato con víctimas del terrorismo que evite la victimización secundaria. Disponible en:

http://www.euskadi.eus/web01-

a2aznscp/eu/k75aWebPublicacionesWar/k75aObtenerPublicacio nDigitalServlet?R01HNoPortal $=$ true $\& N \quad$ LIBR $=051680 \& N \quad$ EDIC $=$ $0001 \&$ C IDIOM=es\&FORMATO $=$.pdf

Group of Experts Against Human Trafficking. (2018). Report concerning the implementation of the Council of Europe Convention on Action against Trafficking in Human Beings by Spain. Disponible en: https://rm.coe.int/greta-2018-7-frg-espen/16808b51e0 
Ilustre Colegio de Abogados de Madrid. (2016). Trata de Seres Humanos: Artículo 177 Bis del Código Penal. Disponible en: http://web.icam.es/bucket/INFORME\%20TRATA\%20DE\%20SER ES\%20HUMANOS.pdf

Instituto de Derechos Humanos Bartolomé de las Casas. (2019). Trata de seres humanos con fines de explotación sexual: un estudio comparado sobre la detección e identificación de las víctimas. Disponible en:

https://clinicajuridicaidhbc.files.wordpress.com/2019/09/inform e-clinicaidhbc-trata-de-seres-humanos.pdf

Ministerios de Justicia, del Interior, de Empleo y Seguridad Social y de Sanidad, Servicios Sociales e Igualdad, Fiscalía General del Estado y el Consejo del Poder Judicial. (2011). Protocolo Marco de Protección a las Víctimas de trata de seres humanos. Disponible en:

https://www.policia.es/trata/pdf/protocolo marco trata.pdf

Naciones Unidas, Oficina contra la Droga y el Delito. (2010). Ley modelo contra la trata de personas. Disponible en: https://www.unodc.org/documents/human-trafficking/TIPModel-Law-Spanish.pdf

Naciones Unidas, Oficina del Alto Comisionado de las para los Refugiados. (2009). Identificación y derivación de las personas víctimas de trata a los procedimientos para la determinación de las necesidades de protección internacional. Disponible en: https://www.refworld.org/cgi-

bin/texis/vtx/rwmain/opendocpdf.pdf?reldoc $=y \& d o c i d=4$ af98bfe $\underline{2}$

Naciones Unidas, Oficina del Alto Comisionado de los Derechos Humanos. (2014). Los Derechos Humanos y la Trata de Personas. Disponible en:

https://www.ohchr.org/documents/publications/fs36 sp.pdf

Naciones Unidas. (2007). Manual para la lucha contra la trata de personas. Disponible en:

https://www.unodc.org/pdf/Trafficking toolkit Spanish.pdf

Red Española Contra la Trata de Personas. (2008). Guía Básica para la identificación, derivación y protección de las personas víctimas de trata con fines de explotación sexual. Disponible en: file:///C:/Users/itzin/Downloads/Guia Basica Identificacion.pdf

United Nations, Office on Drugs and Crime. (2018). Global Report on Trafficking in Persons. Disponible en:

https://www.unodc.org/documents/data-andanalysis/glotip/2018/GLOTiP 2018 BOOK web small.pdf

World Health Organization. (2003). Ethical and safety recommendations for interviewing trafficked women. Disponible en: https://apps.who.int/iris/handle/10665/42765 